\section{AL-AZHAR Dental Journal}

F o r

$\mathrm{G} \quad \mathrm{i} \quad \mathrm{r}$

$\mathrm{S}$
The Official Publication of The Faculty of Dental Medicine For Girls, Al-Azhar University Cairo, Egypt.

Print ISSN 2537-0308 • Online ISSN 2537-0316

ADJ-for Girls, Vol. 8, No. 2, April (2021) — PP. 169:178

\title{
The Influence of Single and Multiple NiTi Rotary File Systems on Prevalence of Postoperative Pain Following Root Canal Instrumentation Using Mechanical or Manual Glide Path Techniques
}

\author{
Shaimaa Rabea ${ }^{*}$, Wael H. Kamel², Mohsen M. Nour El Din ${ }^{3}$, Nehal F. Sharaf ${ }^{4}$
}

\begin{tabular}{|l|} 
Codex : 01/21.04 \\
azhardentj@ azhar.edu.eg \\
http://adjg.journals.ekb.eg \\
\hline DOI: 10.21608/adjg.2020.7493.1083 \\
\hline $\begin{array}{l}\text { Restorative Dentistry } \\
\text { (Removable Prosthodontics, Fixed } \\
\text { Prosthodontics, Endodontics, Dental } \\
\text { Biomaterials, Operative Dentistry) }\end{array}$ \\
\hline
\end{tabular}

\section{KEYWORDS}

K-Files; PathFiles;

ProTaper Next; WaveOne Gold

\begin{abstract}
Purpose: The current investigation was carried out to estimate the influence of single and multiple NiTi rotary file systems on prevalence of postoperative pain following root canal instrumentation using mechanical or manual glide path techniques. Materials and methods: Forty participants with a sympotomatic irreversible pulpitis of mandibular molars were contributed in this randomized, controlled, clinical double blinded study. The participants were assigned into two main groups according to the gliding path system used then further subdivided into two subgroups according to the shaping system used. After access cavity preparation and working length determination, the glide path was prepared using either the PathFiles or the K-Files then the canal shaping was carried out using either the WaveOne Gold or ProTaper Next systems then the root canals were obturated. The postoperative pain was assessed by means of the modified visual analogue scale following 6,12, 24, 48, 72 hours and 7 days then the data were collected and analyzed. Results: Postoperative pain was significantly higher after using the WaveOne Gold and the K-Files. Conclusions: Although all systems caused postoperative pain, the mechanical glide path along with the multi-file continuous rotational systems could be considered as a promising and reliable approach in preparing the root canals with less postoperative pain.
\end{abstract}

- Paper extracted from thesis titled: "The Influence of Single and Multiple NiTi Rotary File Systems on Apical Extrusion of Debris and Incidence of Postoperative Pain after Root Canal Instrumentation"

1. Assistant Researcher of Endodontics, Restorative \& Dental Material Department, National Research Center, Cairo, Egypt

2. Professor and Head of Endodontics, Endodontic Department, Faculty of Dental Medicine for Girls, Al-Azhar University, Cairo, Egypt

3. Professor of Endodontics, Endodontic Department, Faculty of Dental Medicine for Girls, Al-Azhar University, Cairo, Egypt

4. Researcher of Endodontics, Restorative \& Dental Material Department, National Research Center, Cairo, Egypt.

* Corresponding author email: shimaa_rb@yahoo.com 


\section{INTRODUCTION}

Proper root canal treatment noticeably decreases the incidence and intensity of pain, though the severity of the instantaneous postoperative pain may possibly surpass to some extent the pretreatment condition ${ }^{(1)}$. Postoperative inflammatory response and pain could be triggered by the extrusion of dentin chips and debris apically in the course of canal debridement and irrigation ${ }^{(2)}$.

New advances are present nowadays in kinematics of canal shaping either rotation or reciprocation file systems, where many studies have assessed the properties of the instruments. The ProTaper Next multi-file system is made up of a Nickel Titanium alloy with M-Wire technology. Each instrument was designed with variable taper and an asymmetric continuous rotation movement. A swaggering wave of motion is created a long the active portion of the file that aid the dentin chips and debris to be extruded coronary outside the root canal ${ }^{(3)}$.

The WaveOne Gold (WOG) is a super-elastic NiTi single-file system executing reciprocation movement that minimizes torsional and flexural stresses, in addition to the screw effect and taper lock inside the canal ${ }^{(4)}$. In spite of its advantages, some studies reported significant increase in the extruded debris and jeopardy of post treatment pain with the reciprocating instruments when compared to a continuous rotation instrumentation technique ${ }^{(5)}$.

Root canal preflaring and scouting are the primary stages of canal debridement and they are necessary for the securer usage of rotary files. NiTi rotary PathFiles (PF) have been introduced for mechanical preflaring demonstrating less technique sensitivity and invasiveness In comparison to the manual method ${ }^{(6)}$.

Therefore, this study was designed to assess the influence of single and multiple NiTi rotary files on prevalence of postoperative pain following root canal instrumentation using the mechanical or manual glide path techniques.

\section{MATERIAL AND METHODS}

\section{Ethical considerations:}

The study was certified by the Research Ethics committee, Faculty of Dental Medicine for Girls, Al-Azhar University (REC code 16/014) and a signed informed consent form with approval was obtained from each participant.

The patients were selected to fulfill the following criteria:

\section{- Inclusion and exclusion criteria}

Inclusion criteria involved, patient's age between 15-40 years with no sex predilection, patients have a non-contributory medical history, restorable mandibular molar teeth diagnosed clinically and radiographically as asymptomatic irreversible pulpitis with no evidence of apical periodontitis, patients not receiving any palliatives or analgesics before the treatment by 24 hours, and affirmative patient's approval for contribution in the research study.

The exclusion criteria were: pregnant, lactating female patients or patients with psychological disturbance or systemic disease, patients with a positive history of pain, palliatives or analgesics intake, antibiotic use or need antibiotic premedication for dental treatment, patients with periodontal disease, apical abscess, facial swelling or systemic infection, patients with history of allergy to any medication used in the study, teeth with complex anatomy, too narrow or calcified canals and teeth requiring retreatment.

\section{- Randomization, allocation concealment and blinding:}

Random Sequence Generator was used to make the computerized sequence generation for the patient's numbers. The patients were engaged from the outpatient clinic of Endodontic Department, Faculty of Dental Medicine for Girls, Al-Azhar University, Egypt. For the allocation concealment mechanism, 40 papers, (each were eight folded with a number from 1 to 40 ) were placed inside opaque 
sealed envelopes. Before the treatment, each patient was asked to pick up an envelope with a number inside it deciding the type of instrument system that would be utilized for that participant. This research was a double-blinded study, where the participant and the assessor did not know the intervention done. Only the operator knew which intervention 'the system of instrumentation' was done at the time of the endodontic procedures.

\section{- Diagnostic procedures:}

Demographic data including, medical, dental histories and clinical examination data were obtained from every single participant. Chief complaint was recorded in the patient's own words. Overall extra-oral and intra-oral clinical examination was performed. Asymptomatic irreversible pulpitis was diagnosed and detected clinically and radiographically in patients with deep carious lesions reaching the pulp following excavation with the absence of preoperative symptoms. Pulp status either vital or necrotic was assessed and confirmed clinically thereafter by presence or absence of bleeding after opening the access cavity respectively.

\section{- Interventions:}

Strict infection control protocol was performed throughout the whole procedures. Each tooth was anaesthetized (Mepecaine-L Carpule, Alexandria Company for Pharmaceuticals and Chemical Industries, Egypt), upon caries removal the pulp was exposed, and then a straight line access was obtained. The tooth was isolated using rubber dam. A composite build-up restoration was carried out when needed. Then, the working length (WL) was measured using an electronic apex locator (Dentaport ZX; Morita Co, Kyoto, Japan) and then confirmed radigraphically and adjusted to be $0.5-1$ $\mathrm{mm}$ shorter than the radiographic apex.

The root canal orifice was flared using SX file (19/.04) from the Pro-Taper Universal SX (Dentsply Tulsa Dental, Tulsa, OK) in a brushing manner on the outstroke after checking the patency with $\# 10 \mathrm{~K}$ file followed by canal irrigation using $2 \mathrm{~mL}$ of $2.5 \%$ Sodium hypochlorite solution (Clorox, Household Cleaning Products Company of Egypt Ltd, Egypt).

Forty Participants were randomly allocated to one of the two main groups (I\&II) according to the glide path technique used and two subgroups $(A \& B)$ according to the shaping system used.

\section{Group I/Subgroup A: $(\mathbf{n = 1 0})$}

The gliding path was done mechanically in the root canals using NiTi rotary PathFiles (PF) (Dentsply Maillefer, USA), followed by instrumentation using the reciprocating single file WaveOne Gold system (WOG) (Dentsply Maillefer, USA). PF \#1 'purple' (13/0.02) then PF \#2 'white' (16/0.02) and PF \#3 'yellow' (19/0.02) were used at WL by using an endodontic engine ' $\mathrm{X}$-Smart Plus' (Dentsply Maillefer, USA) with 16:1 contra angle at the suggested setting ' $300 \mathrm{rpm}$ on display, $5 \mathrm{Ncm}$ '. The PFs were used in continuous rotation with an outward brushing motion. Then the root canals were instrumented using the reciprocating single file system WaveOne GOLD (25/.07), in a pecking motion, by a dedicated reciprocating motor (X-Smart Plus) that was used with the manufacturer configuration set-up. Based on the initial apical binding file, the master apical file tip size for WOG was standardized at \#25 for narrow canals and WOG Medium (35/.06) for wide canals.

\section{Group I/Subgroup B: $(n=10)$}

The gliding path was done manually in the root canals using the stainless steel (St.St.) hand K-type File (KF) \#15, \#17, \#20 (Mani Inc Utsunomiya, Tochigi, Japan), followed by instrumentation using the reciprocating single file WaveOne Gold system (WOG). KF \#15 (15/0.02) was used, then KF \#17 (Medium sized K-file) (17/0.02) and KF \#20 (20/0.02) with an initial watch winding motion to the point of resistance and then are gently pulled out to remove restricted dentin and debris then followed by a vertical motion till the dentin wall wear away and the file advanced to the working length. Then the root canals were instrumented using the WOG. 


\section{Group II/Subgroup A: (n=10)}

The gliding path was done mechanically in the root canals using NiTi rotary PathFiles (PF), followed by instrumentation using the rotating multifile system the ProTaper Next (PTN) (Dentsply Maillefer, USA). The ProTaper Next (PTN) system was used according to manufacturer instructions with crown down technique. PTN system was used in full sequence rotation with lateral brushing using a torque-controlled endodontic motor (X-Smart Plus) at $300 \mathrm{rpm}$ and a torque of $2.6 \mathrm{Ncm}$. Based on the initial apical binding file, the master apical file tip size for PTN was standardized at \#25 for narrow canals and PTN X4 (40/.06) for wide canals.

\section{Group II/Subgroup B: $(\mathbf{n = 1 0})$}

The gliding path was done manually in the root canals using the K-type Files, followed by instrumentation using the rotating multi-file system the ProTaper Next.

Upon removing any mechanical shaping file from any canal, the canals were irrigated using two milliliters of $2.5 \%$ Sodium hypochlorite solution as an irrigant after each instrument withdrawal for cleaning. Then canals were recapitulated with a size 10 file to break up debris and the glide path was re-confirmed, and then canals were-irrigated. Apical patency was confirmed using a small file (\# 10 $\mathrm{k}$-file) throughout the procedure. A lubricant (Glyde file prep) (Dentsply Maillefer, USA) was used with each file. All the instrumentation systems strictly followed manufacturer's instructions.

Finally, $5 \mathrm{ml}$ of $2.5 \%$ Sodium hypochlorite, $5 \mathrm{ml}$ of $17 \%$ EDTA (ethylenediaminetetraacetic acid) solution (Prevestdenpro, India) for smear layer removal, and $10 \mathrm{ml}$ of distilled water were used as a final flush of the canals. The root canals were obturated using the modified single cone technique. The corresponding sized gutta-percha master cone (Dentsply, Dentsply Maillefer, USA) and the ADSEAL resin root canal sealer (META BIOMED CO., LTD. Chungbuuk, Koriea) were used for obturation.

\section{- Pain assessment and outcomes}

The patients received postoperative instructions and a pain scale form to record the presence or absence and level of the postoperative pain. Pain assessment was done pre and postoperatively using the modified Visual Analogue Scale (VAS) after 6, 12, 24, 48, 72 hours and 7 days. The modified VAS scale expressed pain numerically, verbally and visually. Numerical description represented a 10-point scale, ranging from no pain (score 0) to extreme pain (score 10). Verbal description represented as; No pain (0), Mild pain (1-3), Moderate pain (4-6) and Severe pain (7-10). Visual description represented as graphical logo. Time, number of analgesic tablets intake and degree of pain were recorded. During the follow up periods, there was no loss to follow up $(n=0)$. The patient's collected data from the modified VAS were evaluated by an assessor 'another partner' who wasn't informed which intervention was received. The data of all patients were analyzed.

\section{Statistical analysis}

Numerical data were explored for normality by checking the distribution of data and using tests of normality (Kolmogorov-Smirnov and ShapiroWilk tests). Age data showed normal (parametric) distribution while pain scores showed non-normal (non-parametric) distribution. Data were presented as mean, standard deviation (SD), median and range values. For parametric data, one-way ANOVA was used to compare between all groups. MannWhitney $U$ test was used to compare between the two shaping systems as well as the glide path files. Friedman's test was used to study the changes by time within each group. Dunn's test was used for pair-wise comparisons between the time periods. Qualitative data were presented as frequencies and percentages. Fisher's Exact test was used for comparisons between two shaping systems as well as the glide path files. Friedman's test was used to study the changes by time within each group. The significance level was set at $\mathrm{P} \leq 0.05$. Statistical analysis was performed with IBM ${ }^{\circledR}$ SPSS $^{\circledR}$ Statistics Version 20 for Windows. 


\section{RESULTS}

There was no statistical significant difference regarding mean age values $(P$-value $=0.943)$, gender distributions $(P$-value $=0.715)$ and the number of root canals in the different groups $(P$-value $=0.689)$.

Regarding the VAS pain scores; using the PathFiles, the WOG showed statistically significantly higher mean pain scores than PTN after 6, 12,24\&48 hours. While using the K-Files, the WOG showed statistically significantly higher mean pain scores than PTN after 6, 12, 24, $48 \& 72$ hours (Table 1).

The results revealed that using the WOG; the Path-
Files showed statistically significantly lower mean pain scores than the K-Files after 6, 12, 24 \& 48 hours. Moreover, using the PTN; the PathFiles showed statistically significantly lower mean pain scores than the K-Files after 6, 12 \& 24 hours (Table 1).

Regarding the changes by time in VAS scores for the different groups, there was a pattern characterized by a gradual increase in the VAS pain scores after 6 hours reaching its peak after 12 hours followed by a gradual decrease in pain scores after $12,24,48$ and 72 hours reaching no pain at day 7 (Table 1).

Table (1): Descriptive statistics and results of Mann-Whitney U test for comparison between pain scores of the two shaping systems using PathFiles and K-Files

\begin{tabular}{|c|c|c|c|c|c|c|}
\hline \multirow[b]{2}{*}{ Time } & \multicolumn{3}{|c|}{ Using PathFiles } & \multicolumn{3}{|c|}{ Using K-Files } \\
\hline & $\begin{array}{c}\text { WOG } \\
(\mathrm{n}=10)\end{array}$ & $\begin{array}{c}\text { PTN } \\
(\mathrm{n}=10)\end{array}$ & $P$-value & $\begin{array}{c}\text { WOG } \\
(\mathrm{n}=10)\end{array}$ & $\begin{array}{c}\text { PTN } \\
(\mathrm{n}=10)\end{array}$ & $P$-value \\
\hline \multicolumn{7}{|l|}{ Pre-operative } \\
\hline Mean (SD) & $0(0)$ & $0(0)$ & 1.000 & $0(0)$ & $0(0)$ & 1.000 \\
\hline Median (Range) & $0(0-0)$ & $0(0-0)$ & & $0(0-0)$ & $0(0-0)$ & \\
\hline \multicolumn{7}{|l|}{6 Hours } \\
\hline Mean (SD) & $3.4(0.7)$ & $1.2(0.4)$ & $<0.001 *$ & $6.9(0.3)$ & $2.2(0.4)$ & $<0.001 *$ \\
\hline Median (Range) & $3(3-5)$ & $1(1-2)$ & & $7(6-7)$ & $2(2-3)$ & \\
\hline \multicolumn{7}{|l|}{12 Hours } \\
\hline Mean (SD) & $5.6(1.1)$ & $2.6(0.5)$ & $<0.001^{*}$ & $7.5(0.5)$ & $4.5(0.5)$ & $<0.001 *$ \\
\hline Median (Range) & $5(4-7)$ & $3(2-3)$ & & $7.5(7-8)$ & $4.5(4-5)$ & \\
\hline \multicolumn{7}{|l|}{24 Hours } \\
\hline Mean (SD) & $3.2(0.6)$ & $1.0(0.7)$ & $<0.001 *$ & $6.1(0.7)$ & $3.8(1.1)$ & $<0.001 *$ \\
\hline Median (Range) & $3(2-4)$ & $1(0-2)$ & & $6(5-7)$ & $3.5(2-5)$ & \\
\hline \multicolumn{7}{|l|}{48 Hours } \\
\hline Mean (SD) & $2.0(0.8)$ & $0.5(0.8)$ & $0.002 *$ & $4.1(0.7)$ & $1.2(0.8)$ & $<0.001^{*}$ \\
\hline Median (Range) & $2(1-3)$ & $0(0-2)$ & & $4(3-5)$ & $1(0-2)$ & \\
\hline \multicolumn{7}{|l|}{72 Hours } \\
\hline Mean (SD) & $0.3(0.5)$ & $0(0)$ & 0.067 & $0.9(1.2)$ & $0(0)$ & $0.030 *$ \\
\hline Median (Range) & $0(0-1)$ & $0(0-0)$ & & $0(0-3)$ & $0(0-0)$ & \\
\hline \multicolumn{7}{|l|}{ Day 7} \\
\hline Mean (SD) & $0(0)$ & $0(0)$ & 1.000 & $0(0)$ & $0(0)$ & 1.000 \\
\hline Median (Range) & $0(0-0)$ & $0(0-0)$ & & $0(0-0)$ & $0(0-0)$ & \\
\hline
\end{tabular}


Regarding the severity of pain; using the PathFiles, the WOG showed statistically significantly higher pain severity levels than PTN after 12 \& 48 hours. On the other hand while using the K-Files, the WOG showed statistically significantly higher pain severity levels than PTN after 6, 12, 24 \& 48 hours (Table 2).

The results revealed that using the WOG; the PathFiles showed statistically significantly lower pain severity levels than the K-Files after 6, 12, 24 $\& 48$ hours. Also it revealed that while using the PTN; the PathFiles showed statistically significantly lower pain severity levels than the K-Files 12, 24 \& 48 hours (Table 2).

Regarding changes by time in the levels of pain severity for the different groups, there was a pattern characterized by a gradual increase in the pain severity levels after 6 hours reaching its peak after 12 hours followed by a gradual decrease in pain scores after 12, 24, 48 and 72 hours reaching no pain at day 7 (Table 2 ).

There was no statistical significant difference regarding the medication intake in the different groups.

Table (2): Descriptive statistics and results of Fisher's Exact test for comparison between pain severity levels after using the two shaping systems with PathFiles and K-Files

Using the PathFiles

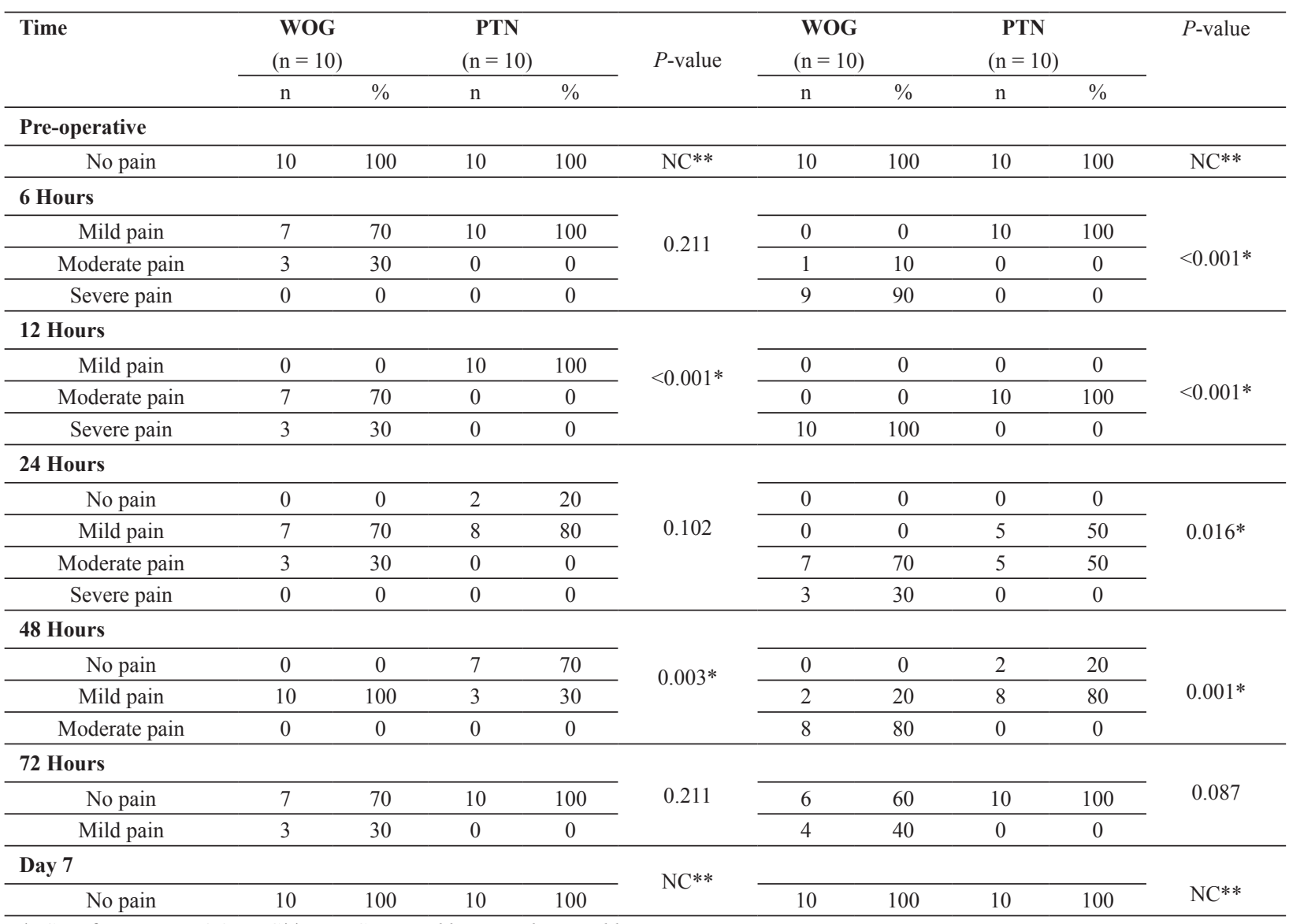

Using the K-Files . 


\section{DISCUSSION}

Obtaining clean, sterile and three dimensionally obturated root canals are the main goals to be attained following the endodontic therapy. In the course of root canal debridement and irrigation; debris as necrotic tissue, bacteria, dentinal chips, and irrigating solutions might be extruded throughout the apex to periapical area ${ }^{(7)}$. The apically extruded infected debris is possibly a principle source of postoperative pain and could have the tendency of disturbing the equilibrium between the defense of the body and the violence of bacteria, ending with incidences of acute pain and flare ups ${ }^{(8)}$.

The purpose of the current study was to assess the influence of single and multiple Nickel Titanium rotary file systems on prevalence of post-endodontic pain following the root canal instrumentation using the mechanical or manual glide path.

In the current study, the analytical results of demographic data revealed no significant difference regarding the mean age value that was in agreement with another study that deduced no age correlation with the prevalence of postoperative pain while that was in disagreement with a recent study which revealed that, old age patients are a high risk group $(9,10)$. Also, the current analysis revealed that gender has no influence on the postoperative pain and complications that coordinated with another study, while it contradicted with another study which reported that female patients are more susceptible to postoperative pain and flare-ups ${ }^{(10,11)}$. There was not one variance as well regarding the number of the treated root canals between groups that coincide with a recent study, but conflict with another one in which the higher postoperative pain associated the teeth with complex root canal anatomy ${ }^{(10,12)}$.

In the present study the VAS pain scores revealed that postoperative pain severity was significantly more intense in participants experiencing canal shaping using WaveOne Gold reciprocating single system when compared with the ProTaper Next rotary multi-file system. The significant difference in POP among the test groups could be due to the apical debris extrusion that is most properly dependent on the instrumentation technique and design ${ }^{(13)}$.

A worm of debris might be extruded during root canal instrumentation periradiculary through the apex. Extrusion of these irritants could provoke an inflammation process as a result of tissue injury (14). There is a straight correlation associating the severity of the inflammation and the severity of tissue injury ${ }^{(15)}$. Activation or release of chemical substances could take place subsequent to tissue injuries that could mediate the inflammation process later on including an increase in vascular permeability and vasodilation etc. Nevertheless, pain may be provoked by thru effect of some mediators on sensory nerve fibers ${ }^{(15)}$.

The increase in vascular permeability is considered to be one of the most important inflammatory consequences that develop postoperative pain. Such increase in vascular permeability could readily promote exudation and edema formation producing hydrostatic pressure that eventually could induce compression on nerve endings and generation of pain ${ }^{(15)}$.

Furthermore, an in vivo study that detected greater release of calcitonin gene-related peptide in the human's periodontal ligament along with substance P subsequent to the usage of the reciprocating system compared with the rotary system ${ }^{(16)}$. It was proposed that the reciprocating system geometrical design promoted more apical extrusion and limited coronal transportation of dentin debris leading to greater neuropeptide concentration. These neuropeptides could lead to neuron's activation or sensitization and peripheral sensitization expressed in the state of spontaneous pain and hyperalagesia ${ }^{(17)}$.

These findings were consistent with those obtained by others ${ }^{(18)}$ who reported greater postoperative pain after utilizing the reciprocating singlefile when judged against the multi-file continuous rotation system, while contrasting with former reports $^{(19,20,21)}$. 
The variances in debris extrusion may be also attributed to the dissimilarities in the movement kinematics and instruments cross-sectional design of each system. The WOG was used in reciprocation movement that is made up of a greater cutting angle $\left(150^{\circ} \mathrm{CCW}\right)$ and a smaller releasing angle $\left(30^{\circ} \mathrm{CW}\right)^{(4)}$; as a consequence, the flutes might not be able to remove the debris out in a coronal direction but forced them apically ${ }^{(22)}$. On the other hand, the PTN system was used in continuous rotation movement that was reported to enhance the coronal carriage of dentine debris and chips via acting as a screw conveyor ${ }^{(23)}$. Besides, the WOG has a parallelogram cross section ${ }^{(4)}$, while PTN has a rectangular cross section ${ }^{(24)}$.

As regards to the influence of the files number in-vivo, a contemporary systematic review and meta-analytic investigation ${ }^{(16)}$, verified that the inflammatory response provoked in vivo is not affected by the files' number 'single, multiple'. However, the movement type and the instrument design have a greater impact on neuropeptide expression in the periodontal ligament ${ }^{(25)}$. These deductions provided an explanation to our findings that exhibit less POP associated with the PTN system 'rotating multi-file system' than the WOG system 'reciprocating single file system'.

Moreover, the VAS pain scores also revealed that, creating a glide path mechanically using the PathFiles induced less postoperative pain when compared with creating it manually using the K-type files.

The significant variance in the postoperative pain could be due to the extruded debris ${ }^{(6,26)}$. The rotary glide path files were found to extrude smaller amount of debris in relation to the manual system ${ }^{(26)}$.

These outcomes coordinated with other investigation $^{(6)}$ in which it was proposed that using hand instrumentation to perform a glide path could exhibit a major influence on the life quality of individuals regarding post-endodontic pain, and proposed that utilizing Nickel Titanium rotating instruments to create a glide path might be quite favorable. The possible explanation is that, the manual $\mathrm{K}$-file acts as a piston extruding the debris apically throughout the apex as limited space is available to urge debris out the canal in a coronal direction ${ }^{(27)}$. While, using rotary PathFiles in continuous rotation and outward brushing motion resembles the act of a screw conveyor by transporting the dentin debris and chips coronary ${ }^{(6)}$.

As regards to the pain intensity experienced by patients within the groups, a pattern was noticed in the present study. The pattern was characterized by an increase of the postoperative pain intensity 6 hours post operatively reaching its peak 12 hours after the therapy, Afterwards, it diminished steadily with no pain at day 7 in all groups. These findings are harmonious with those obtained by other investigators ${ }^{(20,28)}$.

The present results revealed that the WaveOne Gold system was associated with longer pain duration than that with the ProTaper Next system that was consistent with those obtained by another researcher ${ }^{(18)}$. Also, the K-Type Files were associated with longer pain duration than the PathFiles. This coordinated with another study which reported that, the mechanical glide path showed shorter pain duration than the manual glide path ${ }^{(6)}$. On the contrary, it has been reported that, rotary instruments had significantly longer duration of pain than manual instruments ${ }^{(29)}$.

Regarding pain severity, the current study exhibited statistically significant difference in the pain intensity among the groups at the various periods. Patients treated with the reciprocating system using WaveOne Gold and the manual K-type file system as well exhibited significantly greater postoperative pain severity at the different time intervals when compared with those treated with the continuous rotation systems using ProTaper Next and the mechanical PathFile system respectively. These findings could be as a result of the greater apical extrusion of debris ${ }^{(27,30)}$. 
Furthermore; the current analysis revealed no significant difference between the test groups regarding medication intake, which indicates no effect on the primary outcome in agreement with a contemporary research ${ }^{(25)}$, but it was in disagreement with a recent study that publicized more analgesic consumption with manual glide path instruments ${ }^{(18)}$.

\section{CONCLUSIONS}

Within the limitation of this study, the subsequent deductions could be considered: Although all systems caused postoperative pain, the mechanical glide path along with the multi-file continuous rotational systems could be considered as a promising and reliable approach in preparing the root canals with less postoperative pain.

\section{ACKNOWLEDGMENTS}

I would like to express my deepest gratitude, thanks, and appreciation to all my supervisors. I am also grateful to the National Research Center for funding my $\mathrm{PhD}$ research. And finally, I would like to thank all members of Endodontic Department, Faculty of Dental Medicine, Al-Azhar University for Girls, for their help and support.

\section{RECOMMENDATIONS}

Implications for future research:

- More researches isolating the effect of the files number and movement kinematics on the postoperative pain are required.

- Future studies are needed to be considered with larger sample along with registration of the root canal preparation time.

\section{DECLARATION}

\section{There was no conflict of Interest.}

This study was partially funded by the National Research Center, Egypt. Other than that, the authors deny any conflicts of interest in this study.

\section{REFERENCES}

1. Wu H, Peng C, Bai Y, Hu X, Wang L, Li C. Shaping ability of ProTaper Universal, WaveOne and ProTaper Next in simulated L-shaped and S-shaped root canals. BMC Oral Health. 2015; 1:15-27.

2. Ahmed S, Elfar H, El Khodary Sh. Evaluation of Postoperative Pain after Using Sonic Vibringe Irrigation System Versus Conventional syringe irrigation In Single Rooted Teeth with Symptomatic Irreversible Pulpitis: A Randomized Clinical Controlled Trial. Advanced Dental Journal. 2019; 1:86-94

3. Siddique R, Nivedhitha MS, Ranjan M, Jacob B, Solete P. Comparison of antibacterial effectiveness of three rotary file system with different geometry in infected root canals before and after instrumentation-a double-blinded randomized controlled clinical trial. BDJ Open. 2020;8:6-8.

4. Ruddle CJ. Single-File Shaping Technique: Achieving a Gold Medal Result. Dent Today. 2016; 35:98, 100, 102-3.

5. Kurnaz S. Comparison of postoperative pain after foraminal enlargement of necrotic teeth using continuous rotary system and reciprocating instrument: A randomized clinical trial. Niger J Clin Pract. 2020;23:212-8.

6. Pasqualini D, Mollo L, Scotti N, Cantatore G, Castellucci A, Migliaretti G, et al; Postoperative Pain after Manual and Mechanical Glide Path: A Randomized Clinical Trial. J Endod. 2012; 38:32-6.

7. Mohamed AG, Fayyad DM, Mohamed RA. Apical debris extrusion and root canal cleanliness using several rotary nickel titanium files with different kinematica in round and oval canals. DSU. 2020; 1: 39:49.

8. Sharma U, Sharma J, Sharma M, Jain M, Kapoor V. Quantitative Evaluation of Apically Extruded Debris during Root Canal Instrumentation with Reciproc, Wave One, Protaper Universal and One Shape File System - An Invitro Study. EC Dental Science. 2019;18 : 812-22.

9. Pamboo J, Hans M, Kumaraswamy B, Chander S, Bhaskaran S. Incidence and factors associated with flareups in a post graduate programme in the indian population. J Clin Exp Dent. 2014; 6:e514-9.

10. Nair M, Rahul J, Devadathan A, Mathew J. Incidence of Endodontic Flare-ups and Its Related Factors: A Retrospective Study. J Int Soc Prev Community Dent. 2017; 7:175-9.

11. Onay EO, Ungor M, Yazici AC. The evaluation of endodontic flare-ups and their relationship to various risk factors. BMC Oral Health. 2015; 15: 142-6. 
12. Vieyra JP, Enriquez FJJ, Acosta FO. Frequency of postoperative pain in one- versus two-visit endodontic treatment. Endod Prac. 2015; 8:34-9.

13. Çiçek E, Koçak MM, Koçak S, Sağlam BC, Türker SA Postoperative pain intensity after using different instrumentation techniques: a randomized clinical study. J Appl Oral Sci. 2017; 25:20-6.

14. Tüfenkçi P, Yılmaz K, Adigüzel M. Effects of the endodontic access cavity on apical debris extrusion during root canal preparation using different single-file systems. Restor Dent Endod. 2020;45:e33.

15. Siqueira JF Jr, Rôças IN, Favieri A, Machado AG, Gahyva $\mathrm{SM}$, Oliveira JC, et al; Incidence of postoperative pain after intracanal procedures based on an antimicrobial strategy. J Endod. 2002; 28:457-60.

16. Caviedes-Bucheli J, Moreno JO, Carreño CP, Delgado R, Garcia DJ, Solano J, et al; The effect of single-file reciprocating systems on Substance P and Calcitonin gene-related peptide expression in human periodontal ligament. Int Endod J. 2013; 46:419-26.

17. Siqueira, JR JF, Barnett F. Interappointment pain: mechanisms, diagnosis, and treatment. Endodontic Topics. 2004; 7: 93-109.

18. Pasqualini D, Corbella S, Alovisi M, Taschieri S, Del Fabbro M, Migliaretti G, et al; Postoperative quality of life following single-visit root canal treatment performed by rotary or reciprocating instrumentation: a randomized clinical trial. Int Endod J. 2016; 49:1030-9.

19. Comparin D, Moreira EJL, Souza EM, De-Deus G, Arias A, Silva EJNL. Postoperative Pain after Endodontic Retreatment Using Rotary or Reciprocating Instruments: A Randomized Clinical Trial. J Endod. 2017 ;43:1084-8.

20. Kherlakian D, Cunha RS, Ehrhardt IC, Zuolo ML, Kishen A, da Silveira Bueno CE. Comparison of the Incidence of Postoperative Pain after Using 2 Reciprocating Systems and a Continuous Rotary System: A Prospective Randomized Clinical Trial. J Endod. 2016;42:171-6.

21. Shokraneh A, Ajami M, Farhadi N, Hosseini M, Rohani B. Postoperative endodontic pain of three different instrumentation techniques in asymptomatic necrotic mandibu- lar molars with periapical lesion: a prospective, randomized, double-blind clinical trial. Clin Oral Investig. 2017; 21:413-8

22. Alani MA, Al-Huwaizi H .Evaluation of Apically Extruded Debris and Irrigants during Root Canal Preparation using Different Rotary Instrumentation Systems: An In-vitro Comparative Study. Int J Med Res Health Sci. 2019, 8: 21-6.

23. Ameen ITE, Roshdy NN, Fouda MY. Assessment of Apically Extruded Debris of Mesial Root of Lower Molar Using Protaper Rotary Files Versus Hyflex and Neolix Rotary Files (A Comparative Invitro Study). Acta Scientific Dental Sciences. 2020;4.1: 76-81.

24. Omar N, Ismail AG, Galal M, Zaazou MH, Mohamed MA. A comparative finite analysis of the mechanical behavior of ProTaper NEXT and WaveOne rotary files. Bulletin of the National Research Centre. 2019; 43:148, 2-6.

25. Arslan H, Khalilov R, Doğanay E, Karatas E. The effect of various kinematics on postoperative pain after instrumentation: a prospective, randomized clinical study. J Appl Oral Sci. 2016; 24:503-8

26. Topçuoğlu HS, Düzgün S, Akpek F, Topçuoğlu G, Aktı A Influence of a glide path on apical extrusion of debris during canal preparation using single-file systems in curved canals. Int Endod J. 2016; 49: 599-603.

27. Pawar BA, Pawar AM, Atram J, Luke AM, Bhardwaj A, Kfir A, Metzger Z, Wahjuningrum DA. Apical debris extrusion during instrumentation of oval root canals in primary teeth using manual versus motorized files: an ex vivo study. Sci Rep. 2021;16;11:3859.

28. Fatima SA, Moinuddin SM. Pain after single visit endodontic treatment using fifth generation file systems -An in vivo study. Indian J Conserv. Endod. 2017; 2:107-14.

29. Arias A, de la Macorra JC, Hidalgo JJ, Azabal M. Predictive models of pain following root canal treatment: a prospective clinical study. Int Endod J. 2013; 46:784-93.

30. Anous W, Al-Ashry S, Ali MM, Kataia MM. Incidence of postoperative pain after using different kinematic cutting motion in multiple versus single file concept. E.D.J. 2019; 65: 2769: 77 